\title{
PENGARUH PROFESIONALISME, INDEPENDENSI, ETIKA PROFESI, BUDAYA ORGANISASI DAN GAYA KEPEMIMPINAN TERHADAP KINERJA AUDITOR PADA KANTOR AKUNTAN PUBLIK DI PADANG DAN MEDAN
}

\section{THE EFFECT OF PROFESSIONALISM, INDEPENDENCE, PROFESSIONAL ETHICS, ORGANIZATIONAL CULTURE AND LEADERSHIP STYLE ON THE PERFORMANCE OF AUDITORS AT PUBLIC ACCOUNTANT FIRMS IN PADANG AND MEDAN}

\author{
Mega Rahmi \\ Fakultas Ekonomi dan Bisnis Islam IAIN Batusangkar \\ Jl. Sudirman No. 137, Kuburajo, Lima Kaum, Batusangkar \\ e-mail: megarahmi@iainbatusangkar.ac.id
}

Naskah diterima 10 Agustus 2019, di-review 14 September 2019, disetujui 18 Desember 2019

\begin{abstract}
This study aims to determine the effect of professionalism, independence, professional ethics, organizational culture and leadership style of the performance auditor. This type of research is quantitative. The population is all auditors working on a public accounting firm in Padang and Medan incorporated in the Institute of Certified Public Accountants Indonesia totaling 29 public accounting firm of 98 respondents. Source data used are primary data from questionnaires. Data analysis technique using the measurement model, the structural model and the independent samples t-test. Analysis of data using SmartPLS program version 3 and SPSS version 16.The results of this study indicate that the professionalism, independence, professional ethics, organizational culture and leadership style affect the performance of auditors.
\end{abstract}

Keywords: Professionalism, Independence, Professional Ethics, Organizational Culture, Leadership Style, Auditor Performance

\begin{abstract}
Abstrak: Penelitian ini bertujuan untuk mengetahui adanya pengaruh profesionalisme, independensi, etika profesi, budaya organisasi dan gaya kepemimpinan terhadap kinerja auditor. Jenis penelitian ini adalah kuantitatif. Populasi yang digunakan adalah seluruh auditor kantor akuntan publik Padang dan Medan yang tergabung dalam Institut Akuntan Publik Indonesia yang berjumlah 29 Kantor Akuntan Publik dengan jumlah 98 responden. Sumber data yang digunakan adalah data primer. Data diperoleh dari penyebaran kuesioner secara langsung kepada responden.Teknik analisa data menggunakan model pengukuran, model struktural dan independen sampel t-test. Analisis data menggunakan program SmartPLS versi 3 dan SPSS versi 16. Hasil penelitian ini menunjukkan bahwa profesionalisme, independensi, etika profesi, budaya organisasi dan gaya kepemimpinan berpengaruh terhadap kinerja auditor.
\end{abstract}

Kata Kunci: Profesionalisme, Independensi, Etika Profesi, Budaya Organisasi, Gaya Kepemimpinan, Kinerja Auditor

\section{PENDAHULUAN}

$\mathcal{T}$ imbul dan berkembangnya profesi akuntan publik di suatu negara adalah sejalan dengan berkembangnya perusahaan dan berbagai bentuk badan hukum perusahaan. Profesi akuntan publik atau auditor kantor akuntan publik memegang peranan penting dalam perkembangan 
bisnis global saat ini (Rahayuningsih, 2002:234). Profesi akuntan mempunyai peran penting dalam penyediaan informasi keuangan yang handal bagi pemerintah, investor, kreditor, pemegang saham, karyawan, debitur, juga bagi masyarakat dan pihak-pihak lain yang berkepentingan.

Sebagai penunjang keberhasilan dalam menjalankan tugas dan fungsinya dengan baik, sangatlah diperlukan kinerja auditor yang baik dan berkualitas. Kinerja auditor adalah kemampuan dari seorang auditor menghasilkan temuan atau hasil pemeriksaaan dari kegiatan pemeriksaan atas pengelolaan dan tanggung jawab keuangan yang dilakukan dalam satu tim pemeriksaan (Yanhari, 2007). Tercapainya tujuan organisasi tidak hanya dilihat dari kualitas kinerja yang dihasilkan tetapi juga dilihat dari sumber daya yang dimiliki organisasi. Agar tujuan organisasi tercapai, auditor dituntut untuk lebih profesional dalam menjalankan pekerjaannya.

Salah satu kriteria profesionalisme adalah ketepatan waktu penyampaian laporan auditnya. Givoly dan Palmon (1982:490) menyatakan bahwa ketepatan waktu terkait dengan manfaat dari laporan keuangan itu sendiri. Ikhlas (2014) menyatakan bahwa lamanya waktu penyelesaian audit oleh auditor dilihat dari perbedaan waktu tanggal laporan keuangan dengan tanggal opini audit dalam laporan keuangan. Selain auditor dituntut unruk profesional dalam bekerja, auditor juga harus selalu menjaga independensinya.

Rick Antle (1984), menyebutkan bahwa independensi dianggap sebagai atribut penting dari auditor eksternal. Auditor yang menegakkan independensinya, tidak akan terpengaruh oleh berbagai kekuatan yang berasal dari luar diri $168 \mid$ Mega Rahmi auditor dalam mempertimbangkan fakta yang dijumpainya dalam pemeriksaan.

Dalam hal etika, sebuah profesi harus memiliki komitmen moral yang tinggi yang dituangkan dalam bentuk aturan khusus. Kode etik harus dipenuhi dan ditaati oleh setiap profesi yang memberikan jasa pelayanan kepada masyarakat dan merupakan alat kepercayaan bagi masyarakat luas. Dengan demikian dapat disimpulkan bahwa setiap profesional wajib mentaati etika profesinya terkait dengan pelayanan yang diberikan apabila menyangkut kepentingan masyarakat luas.

Budaya organisasi (kerja) adalah sistem nilainilai yang diyakini semua anggota organisasi dan yang dipelajari, diterapkan, serta dikembangkan secara berkesinambungan, berfungsi sebagai sistem perekat, dan dapat dijadikan sebagai acuan berperilaku dalam organisasi untuk mencapai tujuan organisasi yang telah ditetapkan. Budaya organisasi berkaitan dengan sikap atau perilaku seseorang dalam melaksanakan kerja sehari-hari yang bermutu dengan selalu berdasarkan nilainilai yang dianut, sehingga menjadi motivator, memberi inspirasi untuk senantiasa bekerja lebih baik dan memuaskan bagi semua pihak.

Gaya kepemimpinan (leadership style) juga dapat mempengaruhi kinerja. Gaya kepemimpinan merupakan cara pimpinan untuk mempengaruhi orang lain atau bawahannya sedemikian rupa sehingga orang tersebut mau melakukan kehendak pimpinan untuk mencapai tujuan organisasi meskipun secara pribadi hal tersebut mungkin tidak disenangi. Menurut Alberto et al. (2005) dalam Trisnaningsih (2007) 
menyatakan kepemimpinan berpengaruh positif kuat terhadap kinerja.

Baik atau tidaknya kinerja seorang auditor tidak terlepas dari aspek keperilakuan yang dimiliki oleh seorang auditor. Dalam penelitian ini akan dilakukan pengujian secara empiris tentang pengaruh profesionalisme, independensi, etika profesi, budaya organisasi dan gaya kepemimpinan terhadap kinerja auditor. Penelitian ini memiliki perbedaan dengan penelitian sejenis lainnya, karena pada penelitian ini dilakukan pada dua objek yang berbeda yaitu auditor di KAP Padang dan Medan. Dari hasil penelitian ini akan terlihat perbandingan pengaruh variabel keperilakuan terhadap kinerja auditor pada dua objek yang berbeda tersebut. Selain itu juga untuk membuktikan apakah hasil penelitian ini akan sama atau berbeda apabila dilakukan pada auditor yang berbeda sebagai objeknya yaitu auditor yang bekerja pada KAP Padang dan Medan, dimana dengan adanya perbedaan lokasi dan lingkungan kerja pada KAP bisa jadi menyebabkan perbedaan pola pikir dan cara pandang, nilai-nilai yang diyakini ataupun cara auditor bekerja dan secara tidak langsung dapat membawa kepada perbedaan pemahaman tentang bagaimana menghasilkan kinerja yang baik.

\section{KERANGKA KONSEPTUAL}

\section{Profesionalisme}

Hardjana (2002:51) memberikan pengertian bahwa profesional adalah orang yang menjalani profesi sesuai dengan keahlian yang dimilikinya. Dalam hal ini, seorang profesional dipercaya dan dapat didanalkan dalam melaksanakan pekerjaannya sehingga dapat berjalan lancar, baik dan mendatangkan hasil yang diharapkan. Menurut Hall (1998) terdapat lima dimensi profesionalisme yaitu: pengabdian pada profesi, kewajiban sosial, kemandirian, keyakinan pada profesi dan hubungan dengan sesama profesi.

\section{Independensi Auditor}

Akuntan publik berkewajiban untuk jujur tidak hanya kepada manajemen dan pemilik perusahaan, namun juga kepada kreditur dan pihak lain yang meletakkan kepercayaan atas pekerjaan akuntan publik (Christiawan, 2000:13). Jika akuntan tersebut tidak independen terhadap kliennya, maka opininya tidak akan memberikan tambahan apapun (Mautz dan Sharaf, 1961). Jadi, dapat disimpulkan bahwa independensi merupakan sikap seseorang untuk bertindak jujur, tidak memihak, dan melaporkan temuantemuan hanya berdasarkan bukti yang ada.

\section{Etika Profesi}

Arens (2010:67) mendefinisikan etika secara umum sebagai perangkat prinsip moral atau nilai. Perilaku beretika diperlukan oleh masyarakat agar semuanya dapat berjalan secara teratur. Setiap profesi yang memberikan pelayanan jasa pada masyarakat harus memiliki kode etik yang merupakan seperangkat prinsip-prinsip moral yang mengatur tentang perilaku profesional.

Kode etik berkaitan dengan masalah prinsip bahwa auditor harus menjaga, menjunjung dan menjalankan nilai-nilai kebenaran dan moralitas seperti bertanggung jawab 
(responsibility), berintegritas (integrity), bertindak secara obyektif (objectivity), dan menjaga independensinya terhadap kepentingan berbagai pihak (independence) serta berhati-hati dalam menjalankan profesi.Dari penjelasan ini, didapat kesimpulan bahwa etika profesi merupakan perangkat kaidah perilaku sebagai pedoman yang harus dipenuhi dalam mengemban profesi.

\section{Budaya Organisasi}

Menurut Hofstede (1990:294), setiap manusia membawa mental programyangterbentuksejak dini, dari masa kecil di lingkungan keluarga, di lingkungan sekolah dan organisasi. Hofstede (1990:301) membagi budaya organisasional ke dalam enam dimensi: inovasi dan pengambilan resiko, perhatian ke hal yang rinci, orientasi hasil, orientasi orang., orientasi tim/kelompok, keagresifan.

Menurut Mondy dan Noe III (1993:321), terdapat tiga faktor yang membentuk budaya dalam organisasi yaitu: komunikasi, motivasi, kepemimpinan.

\section{Gaya Kepemimpinan}

Gaya kepemimpinan (leadership styles) merupakan cara pimpinan untuk mempengaruhi orang lain/bawahannya sedemikian rupa sehingga orang tersebut mau melakukan kehendak pemimpin untuk mencapai tujuan organisasi meskipun secara pribadi hal tersebut mungkin tidak disenangi (John M Ivancevich,
2006:185). Fleishman dan Peters (1962) dalam Trisnaningsih (2007), menjelaskan bahwa gaya kepemimpinan merupakan pola perilaku konsisten yang diterapkan pemimpin dengan melalui orang lain, yaitu pola perilaku yang ditunjukkan pemimpin pada saat mempengaruhi orang lain seperti yang dipersepsikan orang lain.

\section{Kinerja Auditor}

Teori tentang prestasi kerja lebih banyak mengacu pada teori psikologi yaitu tentang proses tingkah laku kerja seseorang, sehingga seseorang tersebut menghasilkan sesuatu yang menjadi tujuan dari pekerjaannya (Agustia, 2006:104). Kinerja atau prestasi kerja dapat diukur melalui kriteria seperti kualitas, kuantitas, waktu yang dipakai, jabatan yang dipegang, absensi dan keselamatan dalam menjalankan tugas pekerjaan.

Kinerja auditor merupakan tindakan atau pelaksanaan tugas pemeriksaan yang telah diselesaikan oleh auditor dalam kurun waktu tertentu. Pengertian kinerja auditor menurut Mulyadi dan Kanaka (1998:116) adalah auditor yang melaksanakan penugasan pemeriksaan (examination) secara obyektif atas laporan keuangan suatu perusahaan atau organisasi lain dengan tujuan untuk menentukan apakah laporan keuangan tersebut menyajikan secara wajar sesuai dengan prinsip akuntansi yang berlaku umum, dalam semua hal yang material, posisi keuangan dan hasil usaha perusahaan. 
Gambar 1

Kerangka Konseptual

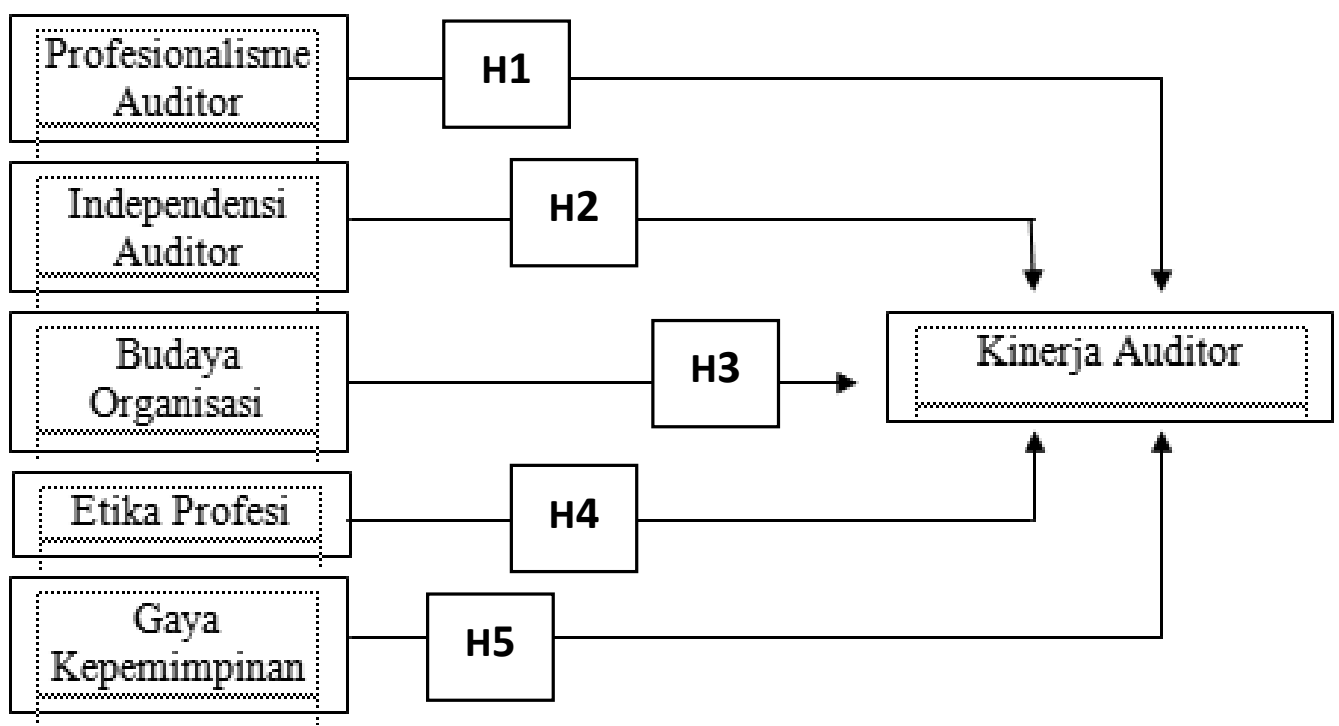

\section{METODE PENELITIAN}

Penelitian ini bertujuan untuk melihat bagaimana pengaruh profesionalisme, independensi auditor, budaya organisasi, etika profesi dan gaya kepemimpinan terhadap kinerja auditor di KAP Padang dan Medan. Dan dengan menggunakan pendekatan kuantitaif sehingga peneliti melakukan pengujian hipotesis (hypotesis testing). Populasi pada penelitian ini adalah auditor yang bekerja pada Kantor Akuntan Publik (KAP) di Padang dan Medan. Auditor yang menjadi sampel dalam penelitian ini dipilih dengan menggunakan teknik purposive sampling dengan jumlah responden sebanyak 98 orang. Data yang digunakan dalam penelitian ini berupa data primer yang berasal dari penyebaran kuesioner kepada masng-masing responden.

Profesionalisme dalam penelitian ini diukur dengan menggunakan instrumen yang dikembangkan Hall (1998): pengabdian pada profesi, kewajiban sosial, kemandirian, keyakinan pada profesi, dan hubungan sesama profesi. Variabel independensi diukur dengan menggunakan instrumen Mauntz and Sharaf (1961): independensi penyusunan program, independensi investigatif, dan independensi pelaporan. Variabel etika profesi menggunakan instrumen Suarniti (2010): kepribadian dan tanggung jawab profesi, integritas, objektifitas, kehati-hatian dan kerahasiaan. Variabel budaya organisasi menggunakan instrumen Supartha (2008): kejelasan nilai-nilai keyakinan, penyebarluasan nilai-nilai keyakinan, intensitas pelaksanaan nilai-nilai inti, kohesi dan komitmen. Variabel gaya kepemimpinan menggunakan instrumen Gibson (1996): kedekatan hubungan, saling percaya, kekeluargaan, saling menghargai gagasan bawahan, komunikasi antar pimpinan dan bawahan, hubungan dalam kelompok, pola dan saluran komunikasi yang jelas dan bagaimana cara mengerjakan tugas yang benar. 
PEMBAHASAN DAN HASIL

\section{Metode Analisis Data}

Penelitian ini menggunakan metode analisis data dengan menggunakan software SmartPLS versi 3.0.m3 untuk melihat pengaruh antara variabel dengan kinerja auditor Berikut uraian mengenai metode analisis data yang penulis gunakan dalam penelitian ini:

Tabel 1

Statistik Deskriptif

\begin{tabular}{|l|l|l|l|l|l|l|}
\hline \multicolumn{1}{|c|}{ Variabel } & \multicolumn{1}{|c|}{ N } & \multicolumn{1}{|c|}{ Min } & \multicolumn{1}{|c|}{ Max } & \multicolumn{1}{|c|}{ Mean } & \multicolumn{1}{c|}{ Median } & \multicolumn{1}{c|}{$\begin{array}{c}\text { Standar } \\
\text { Deviasi }\end{array}$} \\
\hline Profesionalisme & 98 & 55 & 77 & 64,714 & 64 & 4,342 \\
\hline Independensi & 98 & 31 & 44 & 36,837 & 36 & 2,586 \\
\hline Etika Profesi & 98 & 20 & 25 & 21,622 & 21 & 1,898 \\
\hline Budaya Organisasi & 98 & 17 & 25 & 20,214 & 20 & 1,303 \\
\hline Gaya Kepemimpinan & 98 & 27 & 40 & 32,765 & 32 & 2,226 \\
\hline Kinerja & 98 & 16 & 30 & 23,949 & 24 & 2,525 \\
\hline
\end{tabular}

Sumber: Data diolah

\section{Model Pengukuran (Outer Model)}

Outer model sering juga disebut (outer relation atau measurement model) yang mendefinisikan bagaimana setiap blok indikator berhubungan dengan variabel latennya. Model pengukuran digunakan untuk menguji validitas konstruk dan reliabilitas instrumen.

\section{Uji Validitas Konstruk}

Uji validitas dilakukan untuk mengetahui kemampuan instrumen penelitian mengukur apa yang seharusnya diukur.

\section{Uji Validitas Konvergen}

Validitas konvergen dari model pengukuran dengan menggunakan indikator reflektif dinilai berdasarkan loading factor indikator-indikator yang mengukur konstruk tersebut. Parameter uji validitas konvergen dilihat dari skor AVE dan communality, masing-masing harus bernilai di atas 0,5 .

Dari hasil pengujian validitas konvergen didapat hasil bahwa ada 14 item (indikator) yang tidak valid yaitu indikator pada AVE sebanyak 3 item (profesionalisme, independensi dan budaya organisasi) dan loading factor sebanyak 11 item (P3, P4, P11, P13, P14, P15, I1, I4, EP5, B01, dan GK8). Item yang lain telah valid karena nilai loading factor di atas 0,50. Untuk analisis selanjutnya 14 yang tidak valid tersebut harus dikeluarkan karena indikator tersebut tidak termuat (load) ke konstruk yang mewakilinya. Setelah 14 item tersebut dikeluarkan maka diperolehlah hasil dari uji validitas konvergen akhir dengan hasil semua konstruk telah memenuhi kriteria valid.

\section{Uji Validitas Diskriminan}

Pengukuran validitas diskriminan dari model pengukuran dinilai berdasarkan cross loading pengukuran dengan konstruknya, jika korelasi konstruk dengan item pengukuran lebih besar daripada ukuran konstruk lainnya, maka hal itu menunjukkan bahwa konstruk laten memprediksi ukuran pada blok mereka lebih baik daripada ukuran pada blok lainnya. Hasil dari uji validitas terhadap 49 item pertanyaan kuesioner yang 
dilakukan pada 98 responden adalah terdapat 14 indikator yang tidak memenuhi kriteria (rule of thumbs) yaitu indikator pada cross loading sebanyak 14 item (P1, P3, P5, P7, P9, P10, P11, P12, P13, P14, P15, I1, I4 dan I9) sehingga dinyatakan tidak valid. Untuk itu indikator tersebut dikeluarkan dan tidak diikut sertakan pada uji selanjutnya dengan tujuan dapat menaikkan skor pengukuran model (outer loading) masing-masing item dan skor convergen validity.

Setelah item tersebut dikeluarkan maka didapat hasil bahwa nilai cross loading pada menunjukkan adanya discriminant validity yang baik karena semua konstruk telah memenuhi kriteria valid dan nilai korelasi indikator terhadap konstruknya lebih tinggi dibandingkan nilai korelasi indikator dengan konstruk lainnya. Dengan demikian kontruk laten memprediksi indikator pada blok mereka lebih baik dibandingkan dengan indikator di blok yang lain.

Metode lain untuk melihat descriminant validity adalah dengan melihat nilai aquare root of average variance extracted (AVE). Nilai yang disarankan adalah diatas 0,5. Dari pengujian diperoleh hasil bahwa nilai AVE berada di atas 0,5 dan memiliki arti bahwa semua konstruk telah memenuhi kriteria valid. Nilai terendah AVE adalah sebesar 0,604 pada konstruk profesionalisme (P) dan nilai AVE tertinggi sebesar 0,808 pada konstruk Budaya Organisasi (BO).

\section{Uji Reliabilitas}

Uji reliabilitas digunakan untuk mengukur konsistensi alat ukur dalam mengukur suatu konsep atau dapat juga digunakan untuk mengukur konsistensi responden dalam menjawab item pertanyaan dalam kuesioner atau instrumen penelitian. Reliabilitas konstruk dari measurement model dengan indikator reflektif dapat diukur dengan melihat nilai composite reliability dari blok indikator yang mengukur konstruk. Suatu konstruk dikatakan reliabel jika nilai composite reliability di atas 0,70 (Jogiyanto dan Abdillah, 2009:62).

Tabel 2

Composite Reliability

\begin{tabular}{|l|l|l|l|}
\hline \multicolumn{1}{|c|}{ Variabel } & Composite Reliability & Nilai Kritis & Evaluasi Model \\
\hline Profesionalisme & 0,820 & \multirow{5}{*}{$>0,7$} & Reliabel \\
\cline { 1 - 2 } Independensi & 0,936 & Reliabel \\
\cline { 1 - 2 } Etika Profesi & 0,929 & Reliabel \\
\cline { 1 - 2 } Budaya Organisasi & 0,927 & Reliabel \\
\cline { 1 - 2 } Gaya Kepemimpinan & 0,895 & Reliabel \\
\hline Kinerja Auditor & 0,935 & Reliabel \\
\hline
\end{tabular}

Sumber: Data diolah

Tabel diatas menunjukkan bahwa nilai composite reliability untuk semua konstruk adalah diatas 0,7 yang menunjukkan bahwa semua konstruk pada model yang diestimasi memnuhi kriteria reliabel. Nilai composite reliability yang terendah adalah 0,820 pada konstruk profesionalisme (P).Uji reliabilitas juga bisa diperkuat dengan Cronbach's Alpha dimana output SmartPLS versi 3 memberikan hasil sebagai berikut: 
Tabel 3

Cronbach's Alpha

\begin{tabular}{|l|l|l|l|}
\hline \multicolumn{1}{|c|}{ Variabel } & \multicolumn{1}{|c|}{ Cronbach's Alpha } & \multirow{2}{*}{ Nilai Kritis } & Evaluasi Model \\
\hline Profesionalisme & 0,675 & \multirow{4}{*}{$>0,6$} & Reliabel \\
\hline Independensi & 0,920 & Reliabel \\
\hline Etika Profesi & 0,901 & Reliabel \\
\cline { 1 - 1 } Budaya Organisasi & 0,881 & Reliabel \\
\hline Gaya Kepemimpinan & 0,854 & Reliabel \\
\hline Kinerja Auditor & 0,905 & Reliabel \\
\hline
\end{tabular}

Sumber: Data diolah

Nilai yang disarankan adalah di atas 0,6 dan pada tabel di atas menunjukkan bahwa nilai cronbach's alpha untuk semua konstruk berada di atas 0,6 yang menunjukkan bahwa semua konstruk pada model yang diestimasi memenuhi kriteria reliabel. Nilai terendah adalah sebesar 0,675 pada konstruk profesionalisme (P) dan nilai cronbach's alpha yang tertinggi adalah sebesar 0,920 pada konstruk independdensi (I).

\section{Model Struktural (Inner Model)}

Model struktural dalam PLS dievaluasi dengan menggunakan $\mathrm{R}^{2}$ untuk konstruk dependen, nilai koefisien path atau $t$-value tiap path untuk uji signifikansi antar konstruk dalam model struktural. Nilai $\mathrm{R}^{2}$ digunakan untuk mengukur tingkat variasi perubahan variabel independen terhadap variabel dependen. Semakin tinggi nilai $\mathrm{R}^{2}$ berarti semakin baik model prediksi dari model penelitian yang diajukan.

Nilai koefisien path atau inner model menunjukkan tingkat signifikansi dalam pengujian hipotesis. Skor koefisien path atau inner model yang ditunjukkan oleh nilai $t$-statistic harus diatas 1,96 untuk hipotesis dua ekor (two-tailed) dan diatas 1,64 untuk hipotesis satu ekor (one-tailed) untuk pengujian hipotesis pada alpa 5 persen dan power 80 persen (Abdillah, 197: 2015).

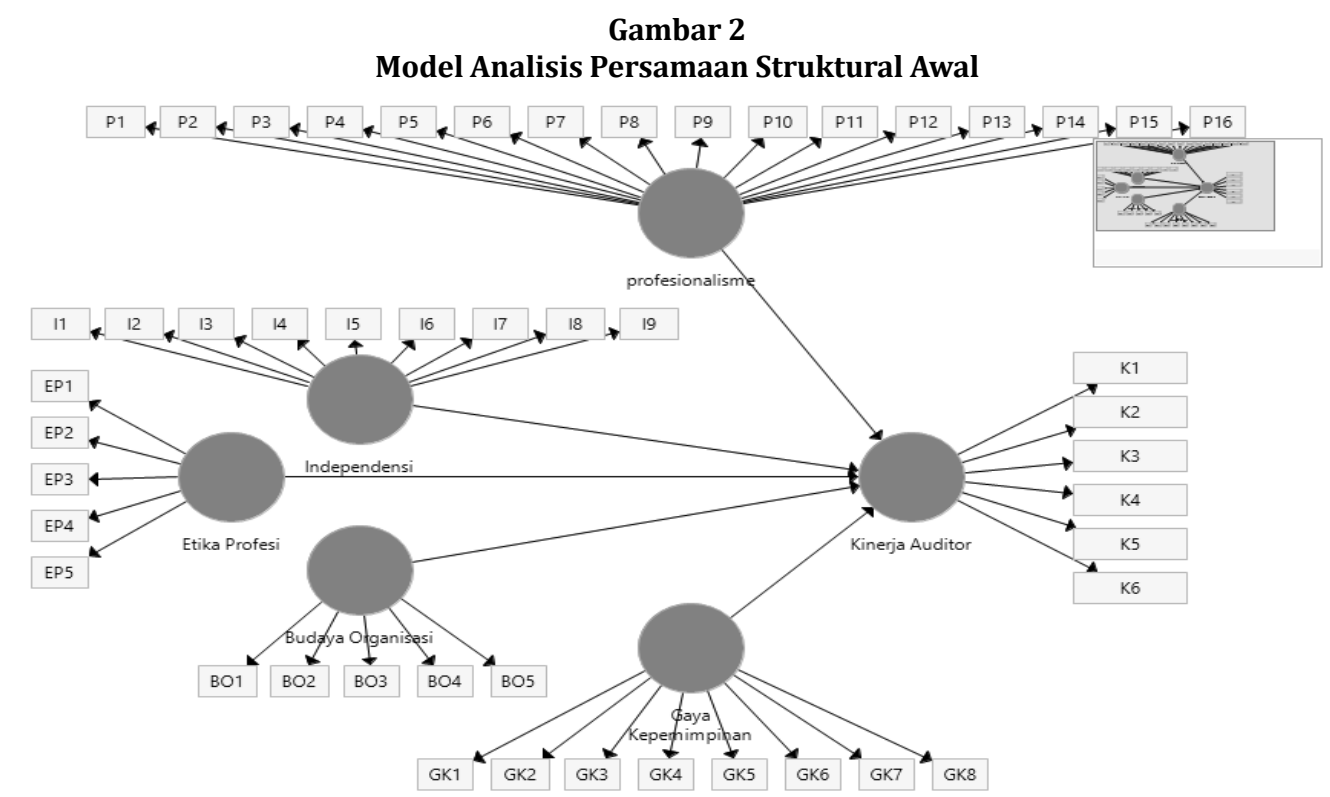

174| Mega Rahmi 
Gambar tersebut menunjukkan bahwa konstruk Profesionalisme (P) diukur dengan 16 indikator, konstruk Independensi (I) diukur dengan 9 indikator, konstruk Etika Profesi (EP) diukiur dengan 5 indikator, konstruk Budaya Organisasi (BO) dengan 5 indikator, konstruk Gaya Kepemimpinan (KP) dengan 8 indikator dan konstruk Kinerja
Auditor (K) diukur dengan 6 indikator Arah panah antara indikator dengan dengan konstruk laten adalah menuju indikator yang menunjukkan bahwa penelitian menggunakan indikator reflektif yang relatif sesuai untuk mengukur persepsi. Hubungan yang akan diteliti (hipotesis) dilambangkan dengan anak panah antara konstruk.

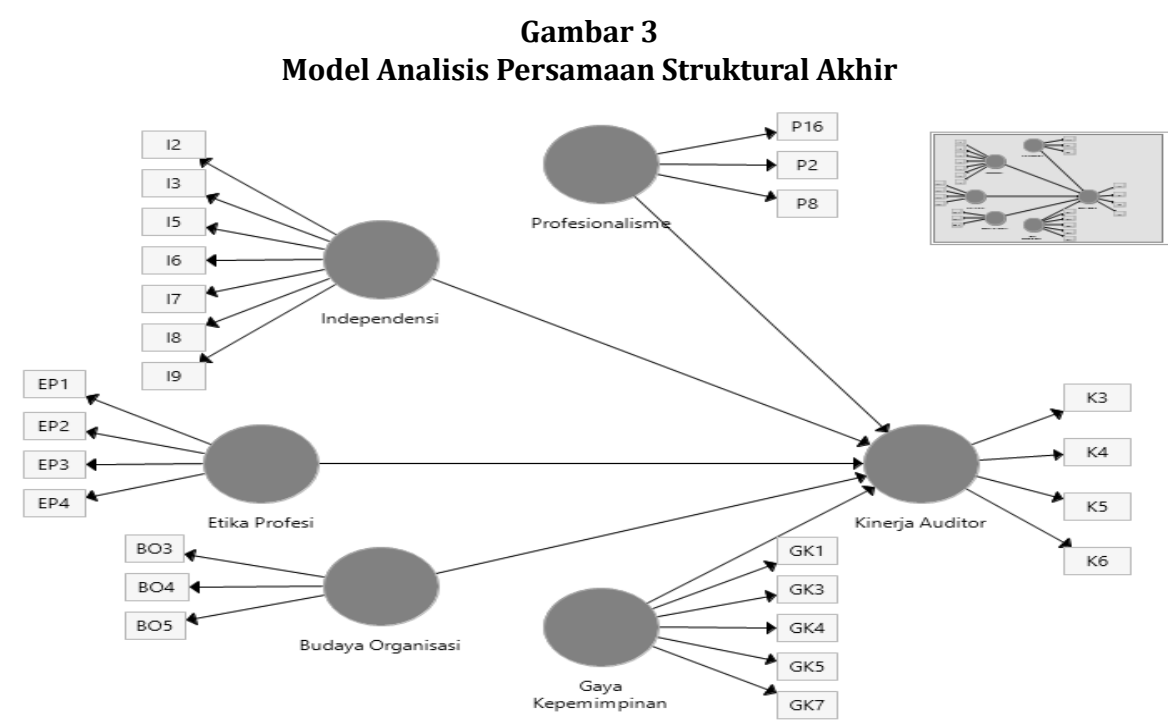

Gambar di atas menunjukkan bahwa ada untukmengukur tingkat variasi perubahan variabel beberapa indikator dari penelitian ini yang independen terhadap variabel dependen. Semakin dikeluarkan atau tidak diikut sertakan pada uji tinggi nilai $R$-square berarti semakin baik model selanjutnya. Selanjutnya nilai $R$-square digunakan prediksi dari model penelitian yang diajukan.

Tabel 4

R-Square

\begin{tabular}{|l|l|}
\hline \multicolumn{1}{|c|}{ Variabel Dependen } & \multicolumn{1}{c|}{ R-Square } \\
\hline Kinerja Auditor & 0.807 \\
\hline
\end{tabular}

\section{Pengujian Hipotesis}

Hasil dari memilih path coefficient (Mean, STDEV, T-Value) akan di dapatkan nilai-nilai inner loading dan $t$-value untuk menilai signifikansi model prediksi seperti berikut ini, dimana signifikansi parameter yang diestimasi memberikan informasi yang sangat berguna mengenai hubungan antara variabel-variabel penelitian.

Tabel 5

Path Coefficient

\begin{tabular}{|l|l|l|l|l|}
\hline & $\begin{array}{l}\text { Original } \\
\text { Sampel }\end{array}$ & $\begin{array}{l}\text { Sampel } \\
\text { Mean }\end{array}$ & $\begin{array}{l}\text { Standar } \\
\text { Deviasi }\end{array}$ & T Statistik \\
\hline
\end{tabular}




\begin{tabular}{|l|l|l|l|l|}
\hline $\begin{array}{l}\text { Profesionalisme } \rightarrow \text { Kinerja } \\
\text { Auditor }\end{array}$ & 0,276 & 0,267 & 0,105 & 2,747 \\
\hline $\begin{array}{l}\text { Independensi } \rightarrow \text { Kinerja } \\
\text { Auditot }\end{array}$ & 0,153 & 0,157 & 0,089 & 3,810 \\
\hline Etika Profesi $\rightarrow$ Kinerja Auditor & 0,034 & 0,073 & 0,092 & 2,097 \\
\hline $\begin{array}{l}\text { Budaya Organisasi } \rightarrow \text { Kinerja } \\
\text { Auditor }\end{array}$ & 0,215 & 0,216 & 0,088 & 2,738 \\
\hline $\begin{array}{l}\text { Gaya Kepemimpinan } \rightarrow \\
\text { Kinerja Auditor }\end{array}$ & 0,332 & 0,332 & 0,072 & 3,526 \\
\hline
\end{tabular}

Tabel diatas dapat digunakan untuk mengukur keterdukungan hipotesis. Ukuran signifikansi keterdukungan hipotesis dapat digunakan perbandingan nilai T-tabel dan T-statistik. Jika nilai T-statistik lebih tinggi dibandingkan nilai T-tabel, berarti hipotesis terdukung. Untuk tingkat keyakinan 95 persen (alpha 5 persen) maka nilai T-tabel untuk hipotesis satu ekor (one tailed) adalah $\geq 1,64$.

Berdasarkan tabel diatas, dapat disimpulkan bahwa hipotesis pertama, kedua, ketiga, keempat dan kelima terdukung atau dapat diterima karena skor T-statistiknya di atas 1,64 yang artinya bahwa profesionalisme berpengaruh positif terhadap kinerja auditor, independensi berpengaruh positif terhadap kinerja auditor, etika profesi berpengaruh positif terhadap kinerja auditor, budaya organisasi berpengaruh positif terhadap kinerja auditor dan gaya kepemimpinan berpengaruh positif terhadap kinerja auditor.

Berdasarkan nilai original sample estimate maka diperoleh nilai tertingi yang mempegaruhi kinerja auditor (K) adalah gaya kepemimpinan (GK) yaitu sebesar 0,332. Hal tersebut menunjukkan bahwa gaya kepemimpinan mempunyai pengaruh terhadap kinerja auditor lebih tinggi dari pada pengaruh antara profesionalisme (P) sebesar 0.276, independensi (I) sebesar 0.153, etika profesi (EP) sebesar 0.034 dan budaya organisasi (BO) sebesar
0.215 terhadap kinerja auditor. Dengan demikian gaya kepemimpinan merupakan variabel yang paling dominan dalam mempengaruhi kinerja auditor. Sedangkan variabel yang paling tidak dominan adalah etika profesi (EP) yaitu dengan original sample estimate terkecil yaitu 0,034.

Dalam PLS pengujian secara statistik setiap hubungan yang dihipotesiskan dilakukan dengan menggunakan simulasi. Dalam hal ini dilakukan metode bootstrap terhadap sampel. Pengujian dengan bootstrap juga dimaksudkan untuk meminimalkan masalah ketidaknormalan data penelitian. Berikut ringkasan hasil pengujian dengan bootstrapping dari analisis PLS:

\section{Pengujian hipotesis (profesionalisme berpengaruh terhadap kinerja auditor)}

Hasil pengujian hipotesis pertama menunjukkan bahwa pengaruh variabel profesionalisme (P) terhadap kinerja auditor (K) menunjukkan nilai koefisien jalur sebesar 0,276 dengan nilai t sebesar 2,747. Nilai tersebut lebih besar dari nilai t tabel $(1,64)$. Hasil ini berarti bahwa profesionalisme berpengaruh positif signifikan terhadap kinerja auditor dan sesuai dengan hipotesis pertama dimana profesionalisme berpengaruh terhadap kinerja auditor. Hal ini berarti hipotesis pertama diterima.

\section{Pengujian hipotesis 2 (independensi}




\section{berpengaruh terhadap kinerja)}

Berdasarkan hasil pengujian hipotesis untuk variabel independensi menunjukkan bahwa pengaruh variabel independensi (I) terhadap kinerja auditor $(\mathrm{K})$ memiliki nilai koefisien jalur sebesar 0,153 dengan nilai t sebesar 3,810. Nilai tersebut lebih besar dari nilai t tabel $(1,64)$. Hasil ini berarti bahwa independensi berpengaruh positif signifikan terhadap kinerja auditor dan sesuai dengan hipotesis kedua dimana independensi berpengaruh terhadap kinerja auditor. Hal ini berarti hipotesis kedua diterima.

\section{Pengujian hipotesis 3 (etika profesi berpengaruh terhadap kinerja)}

Hasil pengujian hipotesis ketiga menunjukkan bahwa pengaruh variabel etika profesi (EP) terhadap kinerja auditor $(\mathrm{K})$ menunjukkan nilai koefisien jalur sebesar 0,034 dengan nilai $t$ sebesar 2,097. Nilai tersebut lebih besar dari nilai $t$ tabel $(1,64)$. Hasil ini berarti bahwa etika profesi berpengaruh positif signifikan terhadap kinerja auditor dan sesuai dengan hipotesis ketiga dimana etika profesi berpengaruh terhadap kinerja auditor. Hal ini berarti hipotesis ketiga diterima.

\section{Pengujian hipotesis 4 (budaya organisasi berpengaruh terhadap kinerja)}

Hasil pengujian hipotesis keempat menunjukkan bahwa pengaruh variabel budaya organisasi (BO) terhadap kinerja auditor (K) menunjukkan nilai koefisien jalur sebesar 0,215 dengan nilai t sebesar 2,738. Nilai tersebut lebih besar dari nilai $t$ tabel $(1,64)$. Hasil ini berarti bahwa budaya organisasi berpengaruh positif signifikan terhadap kinerja auditor dan sesuai dengan hipotesis keempat dimana budaya organisasi berpengaruh terhadap kinerja auditor. Hal ini berarti hipotesis keempat diterima.

\section{Pengujian hipotesis 5 (gaya kepemimpinan berpengaruh terhadap kinerja)}

Hasil pengujian hipotesis kelima menunjukkan bahwa pengaruh variabel gaya kepemimpinan (GK) terhadap kinerja auditor (K) menunjukkan nilai koefisien jalur sebesar 0,332 dengan nilai t sebesar 3,526. Nilai tersebut lebih besar dari nilai t tabel $(1,64)$. Hasil ini berarti bahwa gaya kepemimpinan berpengaruh positif signifikan terhadap kinerja auditor serta sesuai dengan hipotesis kelima dimana gaya kepemimpinan berpengaruh terhadap kinerja auditor. Hal ini berarti hipotesis kelima diterima.

\section{KESIMPULAN}

H1: Profesionalisme berpengaruh positif terhadap kinerja auditor.

H2: Independensi berpengaruh positif terhadap kinerja auditor.

H3: Etika profesi berpengaruh positif terhadap kinerja auditor.

H4: Budaya organisasi berpengaruh positif terhadap kinerja auditor.

H5: Gaya kepemimpinan berpengaruh positif terhadap kinerja auditor.

\section{Keterbatasan Penelitian}

1. Sampel yang digunakan hanya terbatas pada auditor pada Kantor Akuntan Publik (KAP) saja. Keterbatasan ini kemungkinan tidak dapat digunakan sebagai dasar generalisasi 
untuk auditor secara keseluruhan baik dari sektor privat (swasta) maupun sektor publik (pemerintah).

2. Penelitian ini menggunakan metode survey melalui kuesioner, peneliti tidakterlibatlangsung dalam aktivitas di Kantor Akuntan Publik baik di Padang maupun di Medan. Sehingga kesimpulan yang diambil hanya berdasarkan pada data yang dikumpulkan melalui penggunaan instrumen secara tertulis.

3. Penelitian ini hanya menggunakan variabel profesionalisme, independensi, etika profesi, budaya organisasi dan gaya kepemimpinan. Dari hasil analisis diketahui bahwa 80,7\% kinerja auditor dipengaruhi oleh ke lima variabel tesebut. Sedangkan sisanya 19,3\% disebabkan oleh faktor lain. Dengan demikian masih ada variabelvariabel bebas lain yang perlu diindentifikasi untuk menjelaskan kinerja auditor pada Kantor Akuntan Publik di Padang dan Medan.

\section{Implikasi Penelitian}

1. Hasil penelitian inidapatmemberikan kontribusi bagi auditor, penelitian ini dapat menjadi sumber tambahan informasi dalam melaksanakan audit atas laporan keuangan, sehingga dapat meningkatkan prestasi dan kinerja auditor.

2. Auditor diharapkan lebih meningkatkan rasa kepatuhan terhadap etika profesi dalam setiap pelaksanaan proses audit, meningkatkan sikap independensi agar laporan keuangan auditan yang dihasilkan lebih berkualitas serta mampu lebih loyal dan komit terhadap profesi akuntan yang digeluti.

3. Peningkatan kinerja auditor mutlak diperlukan mengingat jasa profesional akuntan semakin pesat dibutuhkan, maka pengembangan pengetahuan auditor perlu dilakukan secara berkelanjutan dengan program pendidikan formal dan pelatihan profesi yang berkelanjutan yang berhubungan dengan tugas pemeriksaan.

4. Megingat profesi akuntan menjadi bidang profesi yang dibutuhkan masyarakat, maka Ikatan akuntan Indonesia memiliki peran penting dalam mengelola dan meningkatkan sumber daya manusia yang dalam hal ini adalah auditor, agar tingkat kepercayaan masyarakat selalu tinggi atas bidang profesi ini.

5. Hasil penelitian ini dapat dijadikan sebagai referensi bagi civitas akademika dalam rangka mengembangkan ilmu pengetahuan khususnya dalam bidang akuntansi keperilakuan.

\section{Rekomendasi untuk Penelitian Selanjutnya}

1. Penelitian selanjutnya mengukur kinerja auditor sebaiknya tidak hanya menggunakan persepsi dari auditor saja, namun juga menggunakan persepsi dari supervisor, pimpinan atau atasan auditor sehingga mendapatkan hasil yang lebih baik.

2. Penelitian selanjutnya dapat memperluas objek penelitian dengan melibatkan auditor pemerintah sehingga dapat dijadikan generalisasi secara keseluruhan.

3. Penelitian selanjutnya perlu menambahkan metode wawancara langsung pada masingmasing responden dalam upaya mengumpulkan data, sehingga dapat menghindari kemungkinan responden tidak objektif dalam mengisi kuisioner. Alangkah baiknya jika penelitian selanjutnya dapat menggunakan metode eksperimen untuk menghindari bias persepsi. 
4. Penelitian selanjutnya dapat menambahkan variabel-variabel lain yang terkait dengan akuntansi keprilakuan sehingga hasil temuannya akan lebih komprehensif.

\section{DAFTAR PUSTAKA}

Abdillah, Willy dan Jogiyanto. 2015. Partial Least Square (PLS) Alternatif Structural Equation Modeling (SEM) dalam Penelitian Bisnis. Ed.1. Yogyakarta: DANI

Agustia, Dian. 2006. Pengaruh Profesionalisme Auditor terhadap Variabel-Variabel Individual Work Outcomes. Majalah Ekonomi, tahun XVI No. 1 April 2006

Arens dan Loebbecke. 2010. Auditing pendekatan Terpadu. Edisi Indonesia. Jakarta: Salemba Empat.

Astriyani, Ni Wayan. 2007. Pengaruh Profesionalisme Auditor terhadap Tingkat Materialitas dalam Pemeriksaan Laporan Keuangan pada Kantor Akuntan Publik di Bali.

Armawan, Made Yudi. 2010. Pengaruh Profesionalisme, Etika Profesi, Tingkat Pendidikan dan Pengalaman Kerja pada Kinerja Pengawas Koperasi Sebagai Internal Auditor (Studi Survei pada Koperasi Simpan Pinjam di Kecamatan Denpasar Selatan).

Bhagat, S dan Black, B. 2001. The Non-Correlation Between Board Independence dan Long Term Firm Performance. Journal of Corporation Law. (27) : 174-231.

Cahyasumirat, Gunawan. 2006. Pengaruh Profesionalisme dan Komitmen Organisasi
Terhadap Kinerja Internal Auditor, Dengan Kepuasan Kerja Sebagai Variabel Intervening. Christiawan, Yulius Jogi. 2000. Konsep Pengauditan dalam Lingkungan Pengelohan Data Akuntansi Terkomputerisasi. Jurnal Akuntansi \& Keuangan, 2(1): h:9-20.

Fanani, Zaenal, Hanif, R. A, dan Subroto, B. 2008. Pengaruh Struktur Audit, Konflik Peran, dan Ketidakjelasan Peran terhadap Kinerja Auditor. Jurnal Akuntansi dan Keuangan Indonesia, 5: 140-155.

Fishbein, M. dan Ajzen, I., 1975. Belief, Attitude, Intentions dan Behavior : An Introduction to Theory dan Research. Addison-Wesely Boston, MA.

Flamholtz, E, dan Narasimhan, R.K. 2005. Differential Impact of Cultural Elements on Financial Performance. European Management Journal, (23) : 50-64

Gani, Achmad. 2006. Pengaruh Gaya Kepemimpinan, Budaya Organisasi dan Motivasi Kerja Terhadap Kinerja Organisasi.

Ghozali, Imam. 2006. Structural Equation Modeling, Metode Alternatif dengan Partial Least Square. Edisi 2. Badan Penerbit Universitas Diponegoro. Semarang.

Ghozali, Imam. 2011. Aplikasi Analisis Multivariat dengan Program IBM SPSS. Edisi 5. Badan Penerbit Universitas Diponegoro. Semarang

Givoly, D. dan Palmon, D. 1982. Timeliness of annual earnings announcements: some empirical evidence. The Accounting Review 57(3). 485508. 
Hair, Joseph F, G. Tomas M. Hult, Christian M. Ringle, Marko Sarstedt. 2013. A Primer on Partial Least Squares Structural Equation Modeling (PLS-SEM). SAGE Publications

Hardjana, Agus. 2002. Pekerja Profesional. Yogyakarta : Kanisius.

Herawaty, Susiana Arleen. 2007. Analisis Pengaruh Independensi, Mekanisme Corporate Gavernance, dan Kualitas Audit terhadap Integritas Laporan Keuangan. Simposium Nasional Akuntansi Vol. X.

Hofstede, G., Bram, N., Denise, D.O. dan Geert, S. 1990. Measuring Organizational Culture: A Qualitative dan Quantitative Study across Twenty Cases. Administrative Science Quarterly. (35) : 286-316

Hopwood, 1974. Accounting dan behaviour. Accounting age book.A Wheaton dan Company.

Ikatan Akuntan Publik Indonesia. 2009. Standar Profesional Akuntan Publik. Jakarta: Salemba Empat.

Ikatan Akuntan Indonesia. www.iaiglobal.orid (diakses tanggal 25 Februari 2016)

Ikhsan Lubis, Arfan. 2005. Akuntansi Keperilakuan. Jakarta : Salemba Empat.

Jensen, M. C dan Meckling, W.H. 1976. Theory of the Firm : Managerial Behavior, Agency Costs dan Ownership Structure. Journal of Financial Economics, Oktober, 1976, V. 3, No. 4, pp. 305360.

Jati, Ardani Mutia. 2009. Pengaruh Independensi, Kompetisi, dan Sensitivitas Etika Profesi Terhadap Produktivitas Kerja Eksternal Auditor.

180 | Mega Rahmi
John M Ivancevich, Robert Konopaske, Michael T Matteson. 2006. Perilaku dan Manajemen Organisasi. Jilid 1 Edisi Ketujuh. Erlangga

Kalbers, Lawrence P., dan Fogarty, Timothy J. 1995. Professionalism Its Consequences: A Study of Internal Auditors.Auditing: A Journal of Practice. Vol. 14. No. 1: 64-86

Khikmah, Siti Noor. 2005. Pengaruh Profesionalisme terhadap Keinginan Berpindah dengan Komitmen Organisasi dan Kepuasan Kerja Sebagai variabel Intervening.

Mangkunegara, Anwar Prabu. 2005. Sumber Daya Manusia perusahaan. Remaja Rosda karya: Bdanung

Mautz, R.K. dan Sharaf, H.A. 1961. The Philosophy of Auditing. American Accounting Association.

Mondy R.W. dan Noe III R.M. 1993. Human Resources Management. Fifth Edition. Needham Height, Massachusettles : Simon dan Schuster, Inc.

Mulyadi dan Kanaka Puradiredja. 1998. Auditing Pendekatan Terpadu. Jakarta. Salemba Empat.

Pramastuti, Suluh. 2006. Perilaku Kepemimpinan Transformasional dan Pengaruhnya terhadap Budaya Organisasi. Jurnal Ekonomi dan Bisnis. Vol. 10 No. 1.

Rachmawati, Sistya. 2008. Pengaruh Faktor Internal dan Eksternal Perusahaan Terhadap Audit Delay dan Timeliness. Jurnal Akuntansi dan Keuangan.

Rahayuningsih, Deasy Ariyanti. 2002. Harapan dan Kenyataan dalam Berkarir di Kantor Akuntan Publik: Suatu Perbdaningan antara Mahasiswa Akuntansi dan Auditor. Jurnal Bisnis dan Akuntansi, 4(3): h:229-252. 
VOLUME 3, NOMOR 2, DESEMBER 2019

Rahmawati. 1997. Hubungan antara profesionalisme internal auditor dengan kinerja, kepuasan kerja, komitmen dan keinginana untuk pindah.

Rick Antle. 1984. Auditor Independence. Journal of Accounting Research.

Robbins, P. Stephen. 2003. Organization Behaviour : Concept, Controversies, Aplications. Seventh Edition. Prentice Hall Inc.

Satyo. 2005. Mendorong Good Governance dengan Mengembangkan Etika di KAP. Media Akuntansi. Edisi Oktober: 39-42.

Siegel dan R. Marconi, 1989, Behavioral Accounting, South-Western Publishing,Ohio.

Sherriton J dan Stren, J.L. 1997. Corporate Culture : Removing the Hidden Barriess to Team Succes, New York : Amacon.

Subekti dan Widiyanti. 2004. Independensi Auditor dan Komitmen Organisasi sebagai Mediasi Pengaruh Pemahaman Good Governance, Gaya Kepemimpinan dan Budaya Organisasi terhadap Kinerja Auditor. Simposium Nasional Akuntansi X. Unhas Makassar 26-28 Juli 2005.

Sugiyono. 2008. Statistika untuk Penelitian. Bdanung: Alfabeta.

Sutrisno. 2006. Pengaruh Budaya Organisasi Terhadap Motivasi Kerja, Komitmen Dan
Kinerja Organisasi. Jurnal Bisnis dan Akuntansi, Vol. 2, No. 3, Desember 2000.

Tridanis, H.C. 1971. Attitudes dan Attitudes Change. Jhon Waley dan Sons, Inc, New York. Trisnaningsih, S,. 2007. Perbedaan Kinerja Auditor Dilihat dari Segi Gender. Jurnal Riset Akuntansi Indonesia.

Tuanakotta, Theodorus M. 2015. Audit Komtemporer. Salemba Empat. Jakarta

Vroom, Victor H. 1964. Work dan Motivation, New York : John Wiley \& Son, Inc.,

Wibowo, Hian Ayu Oceani. 2009. Pengaruh Independensi Auditor, Komitmen Organisasi, Gaya Kepemimpinan, dan Pemahaman Good Governance terhadap Kinerja Auditor (Studi Empiris pada Kantor Akuntan Publik di Daerah Istimewa Yogyakarta).

Yanhari. 2007. Analisis Profesionalisme dan Etika Profesi Auditor terhadap kinerja Auditor (Studi Kasus pada Badan Pemeriksa Keuangan RI di Jakarta).

Yanthi, Ida Ayu Putu Danres. 2011. Pengaruh Independensi Auditor, Etika Profesi dan Gaya Kepemimpinan Terhadap Kinerja Auditor Pada Kantor Akuntan Publik di Bali. 